\title{
A Strange Transamerican Optimism
}

ANDREW SANTA LUCIA

School of the Art Institute of Chicago

\begin{abstract}
A contemporary strand of Transamerican architects working between the American continents have developed a discernible attitude towards architecture, a Strange Optimism, a radical agenda of novel social participation encompassed by progressive architectural instrumentality. This work runs counter to the more accepted genealogies of Latin American architecture and its utilitarian, political or contextual in the second half of the 20th century. This essay will define a Strange Transamerican Optimism in the work of Sydney/New York/Madrid's Fake Industries Architectural Agonism, Mexico's Pedro y Juana and Bolivia's Freddy Mamani Silvestre.
\end{abstract}

\section{INTRODUCTION}

"... art that aims to produce a new perception of the world...create(s) a commitment to its transformation. This schema, very simple in appearance, is actually the conjunction of three processes: first, the production of a sensory form of 'strangeness'; second, the development of an awareness of the reason for that strangeness and third, a mobilization of individuals as a result of that awareness."

- Jacques Ranciere, Dissensus: On Politics and Aesthetics

As Reyner Banham helped introduce British Brutalism to a wider design culture in 1955, he disclaimed that placing an observer - him - into any field of forces - Brutalism - would essentially distort that field. ${ }^{1}$ This study attempts a productive distortion of late-modern architectural origins in Latin America and a close interpretation of three contemporary Transamerican projects that help redefine architecture in the Americas. Today, a loose mobilization of architectural practices from within the North, Central and South American continents, resisting popular models of practice are instead developing a nuanced series of design ideas that redefine architectural discipline's place in the mediation of Transamerican culture. ${ }^{2} \quad$ Although different, these practices are producing highly aestheticized projects that share two common themes: they are invested in a purposeful strangeness vis-à-vis their cultural contexts; and they make a claim about architecture's optimistic instrumentality in creating new participatory models in the Americas.

In this way, Strange Optimism is a discourse between culture and shape linking (1) Ranciere's theories on critical art, namely the introduction of an atypical and strange product, to the (2) highly public ways the Transamerican architects examined in this study instrumentalize their architectures. ${ }^{3} \mathrm{~A}$ progressive instrumentality is focused on particular disciplinary tools and their 1-to-1 relationship to the ways people participate with architecture. This link is explored through an aesthetic and participatory analysis of three distinct instrumentalities evident in Pedro y Juana's Dear Randolph in Chicago, Illinois; Freddy Mamani Silvestre's Salones de Eventos in El Atlo, Bolivia; and Fake Industries Architectural Agonism's Velodrome in Medellin, Colombia.

An equally important reason to develop a theory of Strange Optimism is because of dominant historiographies surrounding Latin American architecture from the technocratic to the utilitarian and from the geometric to the geopolitical. The global effect of government sponsored Developmentalism in countries like Chile, Argentina, Mexico, Venezuela and Brazil were happenstance after 1945, leading to both the popular understanding of Latin American architecture as interested in concrete and Brutalist housing; and ultimately to the Neo-Liberal policies that paved the way for much of the urban malaise that exists today. ${ }^{4}$ Obviously, the ability for Latin American building practices to deal with complex social issues are canonical and not understated here. However, by repositioning other later Latin American Modernisms, which provided singular and plastic alternatives towards the more broadly popular goals of utility, universality and equity, a genealogy of Strange Optimism is evident.

\section{LATE MODERN, POETICALLY STRANGE}

A Global architectural history is filled with soirees between architecture and other disciplines. However, the integration of poetry into late-modern architectural discourse in Latin America provided an avenue towards a Strange Optimism. The use of poetry in more literal ways is explored here in the Latin American projects of Brazil's Lina Bo Bardi, Cuba's Ricardo Porro, and La Pontificia Universidad Catolica de Valparaiso's La Ciudad Abierta in Ritoque, Chile. 


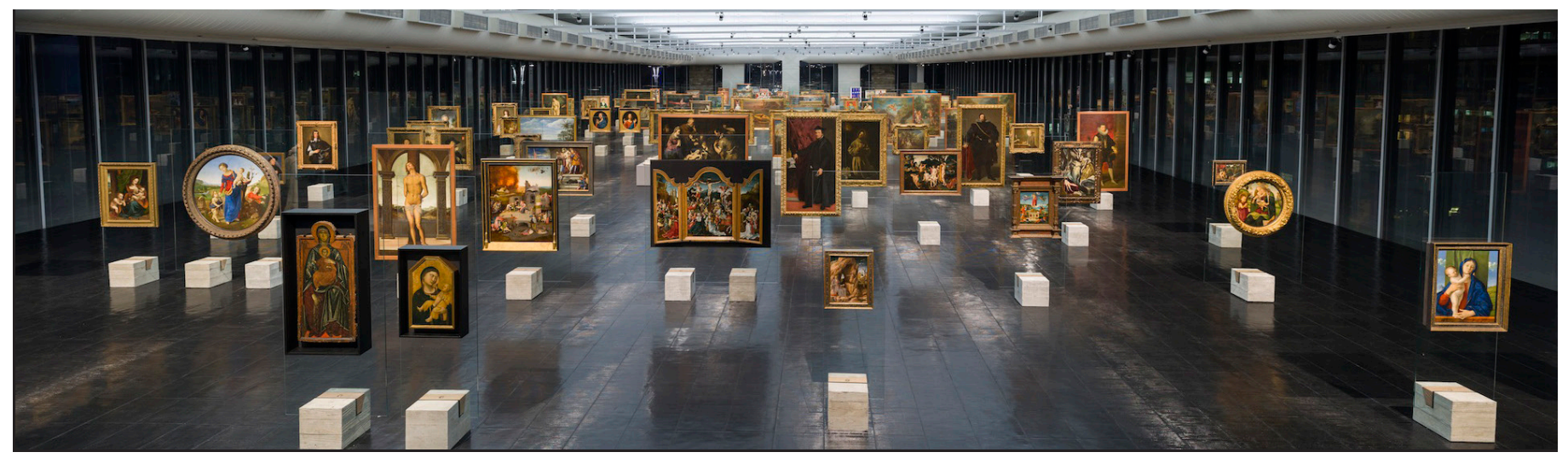

Figure 1: Sao Paolo Museum of Art, Main Gallery space with Glass Easels, Lina Bo Bardi, 1968

As a Brazilian modern master, Lina Bo Bardi's work is of particular importance here because of her mantra, 'I never look for beauty, only poetry.' ${ }^{5}$ Marcelo Ferraz regarding Bo Bardi's design process, states that,

"unburdened, but as provocative as ever, Bo Bardi rejected the hegemony - or the mystification - of the architectural drawing, as the ultimate form of self expression. She claimed that she could produce a project purely in writing and have it built. ${ }^{6}$

While polemical, this statement seems to merge structural linguistics and poetry as a sentiment underlining both method and expression. Perhaps, this is most apparent in her 1968 Sao Paolo Museum of Art main gallery space, where her design for Glass Easels hold up paintings, removing the wall as the main mediation of space in the museum and 'freeing the art.' 7 People move through a complex and malleable series of human sized pedestals that seem more like an army in formation than a museum collection, suggesting a particular scalar relationship to how people and art interact. The pedestal base is made of concrete with a wooden connection joint that receives glass panels which hold the paintings. The Glass Easels are scalable to fit various painting sizes and employ a perverse materiality. From designed object to adaptive reuse technique, Bo Bardi's 1982 SESC Pompeia can be read as a project of figuration in architecture. Her fenestration is distinct and figural, not dissimilar from shapes used prior by Le Corbusier or during and later by John Hejduk, except deployed in a controlled demolition window treatment of an existing factory concrete wall. This sort of figuration is formal but not figurative.

In addition to Bo Bardi's use of poetry as method, a more literal and figurative version of the poetic was being produced in Latin America simultaneously. Cuban Modernist architect Ricardo Porro's 1970 design for a Children's school in Vaduz, Liechenstein, shows an obsession with anthropomorphic figures through plan, where a male torso and arms create a landscape condition. Another example of the strange poetic dimension is visible in Porro's most famous buildings, the School of Plastic Arts and the School of Modern Dance in Havana, Cuba.
Architect John A. Loomis writes that, "Porro's poetically interpretive reading of Cuban history provided a theoretical framework for a formal elaboration of cultural themes heretofore unknown in Cuban architecture." ${ }^{8}$ Porro literally used his School of Plastic Arts and School of Modern Dance as an encapsulation of the great fervor around the revolutionary poetry and liberation happening in post1959 Cuba. The plan for the School of Modern Dance employs a series of elliptical halls organized along curvilinear walkways, reminiscent of an African village that Porro used to create an alternative narrative centered on Afro-Cuban heritage, rather than Spanish colonization. ${ }^{9}$ He goes on to use a series of complex splines in plan, curving trusses in section and various domes to engage, reflect and mimic the program of the building, creating a truly rhythmic space for dancing and art.

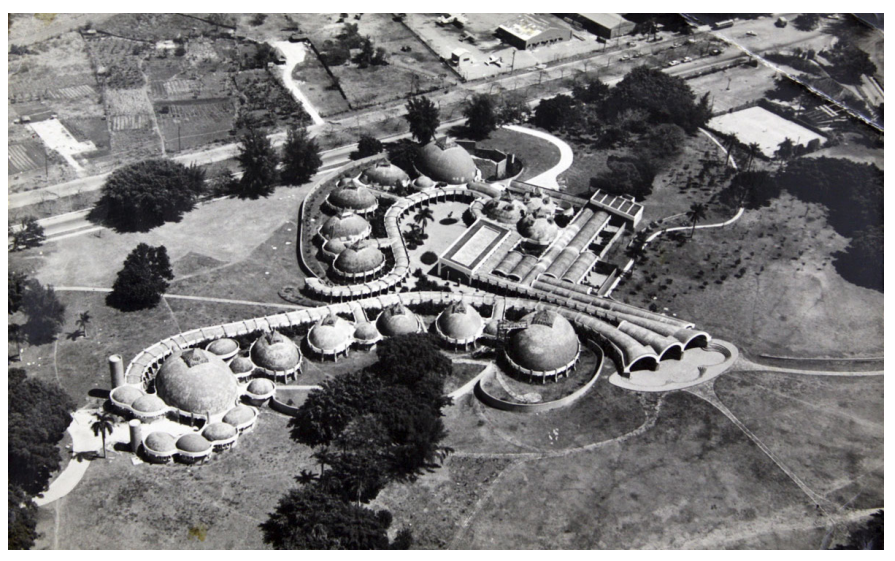

Figure 2: School of Plastic Arts, Havana, Cuba. Ricardo Porro, 1961

Finally, Amereida, a collectively written poem published in Chile in 1967 became the foundational and conceptual text of the La Ciudad Abierta, the iconic design-build territory northwest of Santiago de Chile and second home to La Universidad Catolica of Valparaiso. To publicize the legendary trip that faculty and students were about to take from Patagonia to Ritoque, north of Valparaiso, an advertisement entitled Poetagoonia, showed the relationship between poetry and architectural fervor. ${ }^{10}$ Poetry provided students and faculty an escape from adherence to modernist principles, whilst at the same time loosening its grip on regional practice, almost as a release valve. 
The first built project of La Ciudad Abierta was completed in 1972 and now houses over 20 functioning buildings and structures that are as free and open as Amereida's initial call to action.

These Strange Optimist roots show a union between the aesthetic and the political through novel experimentation, as an expression of emergent cultural attitudes enabled by architecture. The following three projects define instrumentality in an optimistic way and anchored by participatory models that are strange vis-à-vis their cultural contexts.

\section{A MALLEABLE CEILING PLANE IN URBAN INTERIORS}

According to Pedro y Juana, their design practice 'do(es) architecture, did art, make(s) things, digital and/or not, (and are) out of Mexico city and elsewhere.' ${ }^{11}$ Their attitude towards the many different contexts for their work, as well as the varied types of projects they create feeds into the Transamerican narrative of producing between the continents, without a particular interest in the global and evidently a stronger relation to the local, as evidenced by their latest project in Chicago.

Directed by Mexico City-based designers Ana Paula Ruiz Galindo and Mecky Reuss, Pedro y Juana were invited to produce a public interior for the 2015 Chicago Architecture Biennial hosted inside the 1896 Beaux Arts style, Chicago Cultural Center. Pedro y Juana's site was the Garland room, locally referred to as Chicago's living room because of high visitor traffic daily from downtown businesspersons, tourists and homeless citizens using free internet and public facilities. Before the advent of their design project, Pedro y Juana penned a love letter to the Garland room entitled Dear Randolph, creating a fiction around their site, a soft form of poetic foundation for making Randolph Square.

The interior was replete with custom furniture's that include a modular table design with UFO-like legs, as well couches and rocking chairs made of transparent aluminum mesh. The fulcrum of their project comes in the form of a malleable ceiling plan and lighting system. The ceiling system was composed of floating orb lights, organized on a complex series of pulley systems with varied hanging weights that connect to other pulley points/weights in other sections of the room and can be manipulated by visitors to the space. This complex dance of orange lights and yellow ropes hover sometimes inches away from people lounging.

The lights themselves have one fixed connection point with three ropes attached to weights and pulleys, giving visitors an almost endless number of configurations, depending on when and where someone is pulling on the weights. Throughout a seating session, a person might see 50 different ceilings in a space that always had just one. However, the most compelling moments were when visitors would misuse the system. A personal favorite was when a Tai-chi instructor grabbed weights and proceeded to practice her - aptly named - forms, subsequently being translated into an architectural situation through the ceiling canopy. This form of participation provided visitors with not only the ability to modify their environments a few lights at a time, but also allowed architects to give up responsibility of of lighting schemes on an hourly basis to people, something that most certainly is seen as a strange occurrence in conventional architectural production. Finally, the wallpaper treatment chosen for Randolph Square employed a custom-graphic that included a mixture of ornate filigree, which reflected in elevation the ceiling of the Garland room and references to books giving visitors another reading of the building's history when it was a library in the 20th century.

Pedro y Juana provided Biennial-goers with a complex, but familiar space. At times, the buildings history played an integral role in the definition of their project and at others provided them with strange juxtapositions that allowed a late-19th century Beaux Arts room to turn into an interactive space filled with micro-territories of study, leisure and play, transplanting ideas like traffic, networks and participatory politics into lighting systems, furniture and urban interiors.

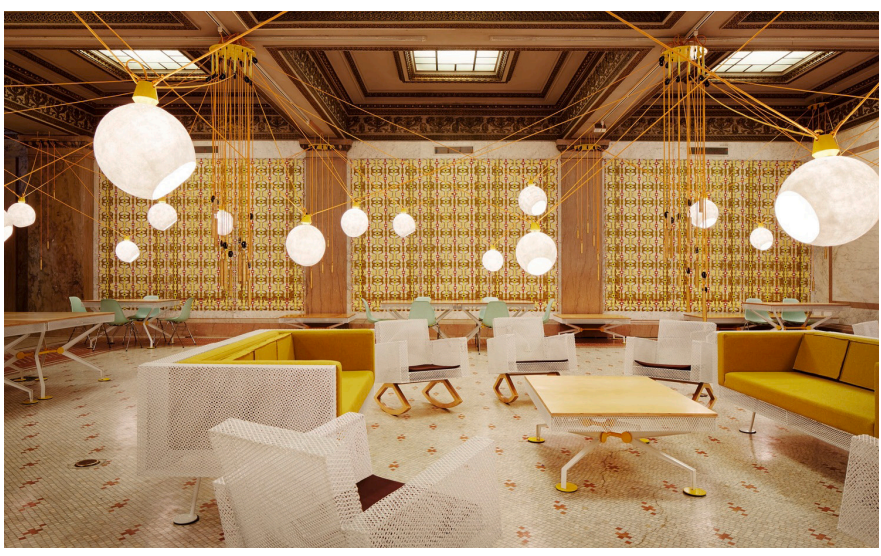

Figure 3: Randolph Square, custom furniture, wallpaper and malleable lighting system. Pedro y Juana, 2015.

\section{INDIGENOUS SUPERGRAPHICAL PUBLIC PARTY BUILDINGS}

In the very first caption of Bernard Rudofsky's seminal Architecture without Architects, he states that,

"Vernacular architecture does not go through fashion cycles. It is nearly immutable, indeed, unprovable since it serves its purposes to perfection. As a rule, the origin of indigenous building forms and construction methods is lost in the distant past." 12

This easily missed section of text precedes a canon, but is telling of the author's inability to see a third type of vernacular architecture (and builder) born out of indigenous pride, developing economic means and a dedication to new forms of aesthetic rigor. Freddy Mamani Silvestre is an Aymaran architect and builder that has produced a fashionable indigenous oeuvre, a Neo-Andean architecture. This work is entirely completed in El Alto, Bolivia's fastest growing city and exalts the shifting class dynamics for the Aymara people after the election of Evo Morales, Bolivia's first indigenous President. Critic Elisabetta Andreoli states that, "What differentiates El Alto from other rapidly developing urban zones is the high level of social organization and the role this plays in structuring the city," which means 


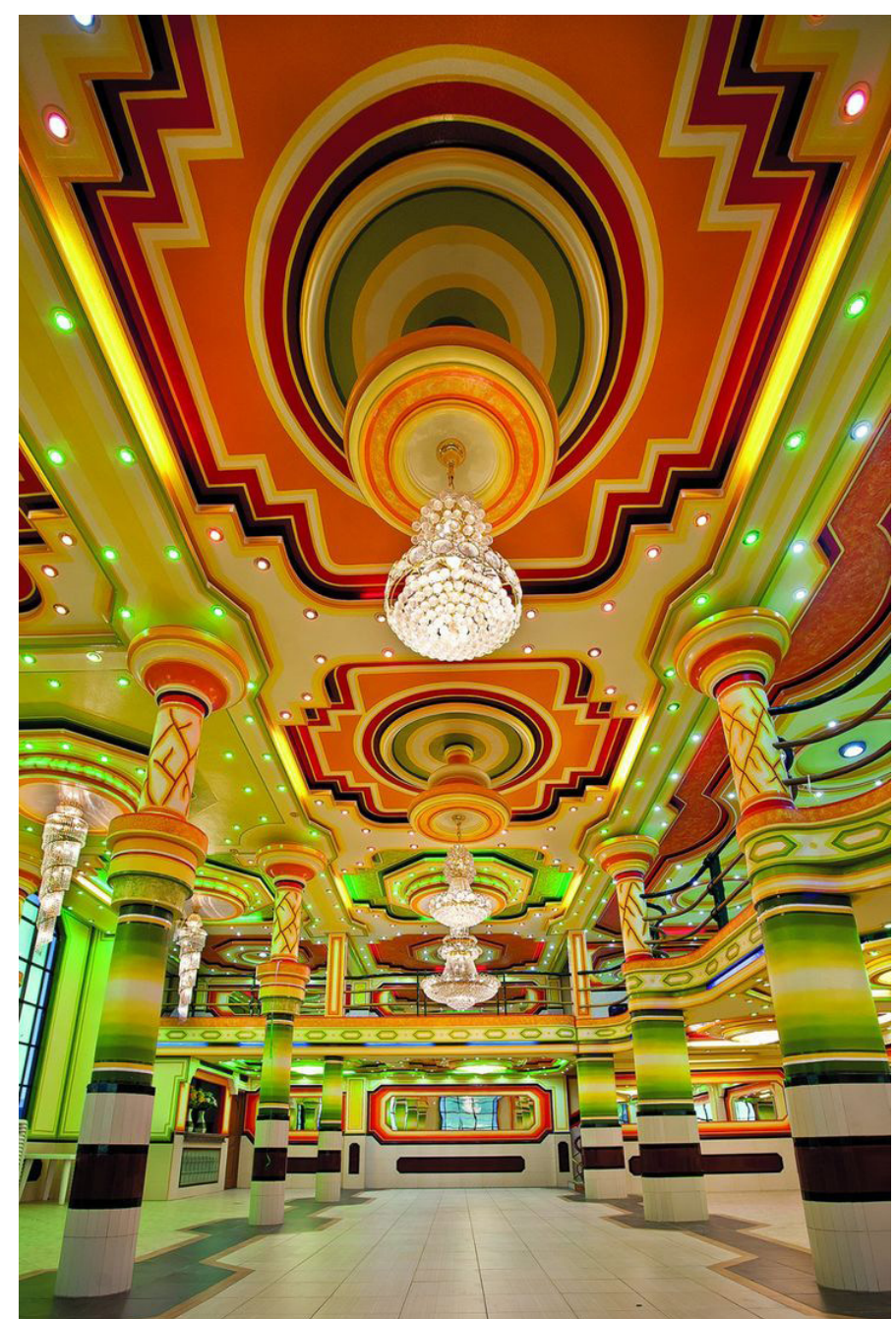

Figure 4: Interior of a Salon de Evento in El Alto, Boliva. Freddy Mamani Silvestre, 2011.

participation is a key element in Mamani's work, but also hardwired into the fabric of El Alto's urbanization. ${ }^{13}$ In effect, he has created Salones de Eventos \& Chalets, which are neo-postmodern, culturally supergraphic and multi-story shape-driven public party buildings with private houses on top. ${ }^{14}$

Mamani uses Aymaran history as a foundation for his aesthetic approach to building. The archaeological site of Tiwanaku, Bolivia, is commonly known to be the "Spiritual Capital of the Aymara People" and home to the highly graphical Pachamama Monolith, discovered in $1932 .{ }^{15}$ A legend Mamani tells is that he visited the site before his first large commission in 2005, only then deciding to incorporate the pattern, graphic language and traditional color palettes of the Aymara into his architecture. ${ }^{16}$ Mamani sees his architecture as an expression of his cultural identity. In addition, he states that,

"There have always been rich Aymaras. The problem was they didn't identify with it... Now, with this architecture they come to the fore saying, 'We are Bolivians, we are Aymara and we can show off our new Indigenous Bolivian confidence."
Perhaps, one reading of his architecture is that it has engendered the outward expression of Aymara pride.

The new middle class Aymara are the owners of the Chalets and rent the Salones de Eventos spaces out weekly. Salon EI Tren represents Mamani's typical building design. The building parti is almost always the same in section, with small commercial spaces located on the ground floor; the main Salon de Evento on the second and third floors open to below; private penthouses reserved for the children of the building owner or rentable to party goers on the fourth and firth floors; and finally a house, or chalet, placed on top of the building where the owner lives. A strong identifier of his buildings is the intense visual language on the façade, a mixture of painted graphics and minor tectonic extrusion, clad in reflective colored glass.

Mamani's interiors are even more expressive than his building skins. Every square inch of horizontal and vertical surface is painted, using Aymara motif and color. The surfaces themselves are complex, but not complicated. The addition of optical effects create depth using mild physical extrusions, paints and colorful LED lights. A bulk of Mamani's main employees are professional artists, not solely building painters. His interiors have become more spectacular, evolving into novel and nuanced design motifs within Mamani's canon, but definitely evolving authentically. The variation in shape, size, color and pattern depend not only on Mamani's aesthetic interest, but also the cultural and pop interests of his clients, sometimes asking for motifs such as shapes that resemble the Transformer movies. One of Mamani's recent Salones de Eventos, Crusero del Sur, resembles a cruise ship covered in Aymaran figures. Mamani has created a truly strange participatory phenomenon for-and-by Aymarans, through the introduction of postmodern shapes in his architecture and a graphical aesthetic that envelopes visitors in a smooth atmosphere reflecting their collective gains as a culture.

\section{PARTICIPATORY FACADE VIA BIKES IN A VELODROME}

In 2012, Fake Industries Architectural Agonism, out of Sydney, Australia; New York, NY; and Madrid, Spain, won an international competition to design a velodrome park in Medellin, Colombia. Urtzi Grau, co-director of FKAA, states that, "Velodromes are infrastructures that by definition are underused - 30-35 days a year and mostly empty. Can we immerse users in a model that is closed when an event is inside, but used freely openly the rest of time." 17 In addition, FKAA's proposal takes advantage of the progressive political tactic Medellin's city government has taken in the last 11 years, with the introduction of its neighborhood Library Parks. For each new park, a Team of sociologists are integrated into the design team to monitor and facilitate interaction with community members.

"The local government of Medellin makes a serious claim about what participation in a design process is," states Grau. In this case, libraries provide the vehicle to create neighborhood icons, identifiable architectures that are local giving citizens a chance to rally around their public spaces. By engaging this neo-liberal public works process, FKAA has been able to produce a machine-like architecture that engages the growing popular culture of cycling in Colombia and provides a 


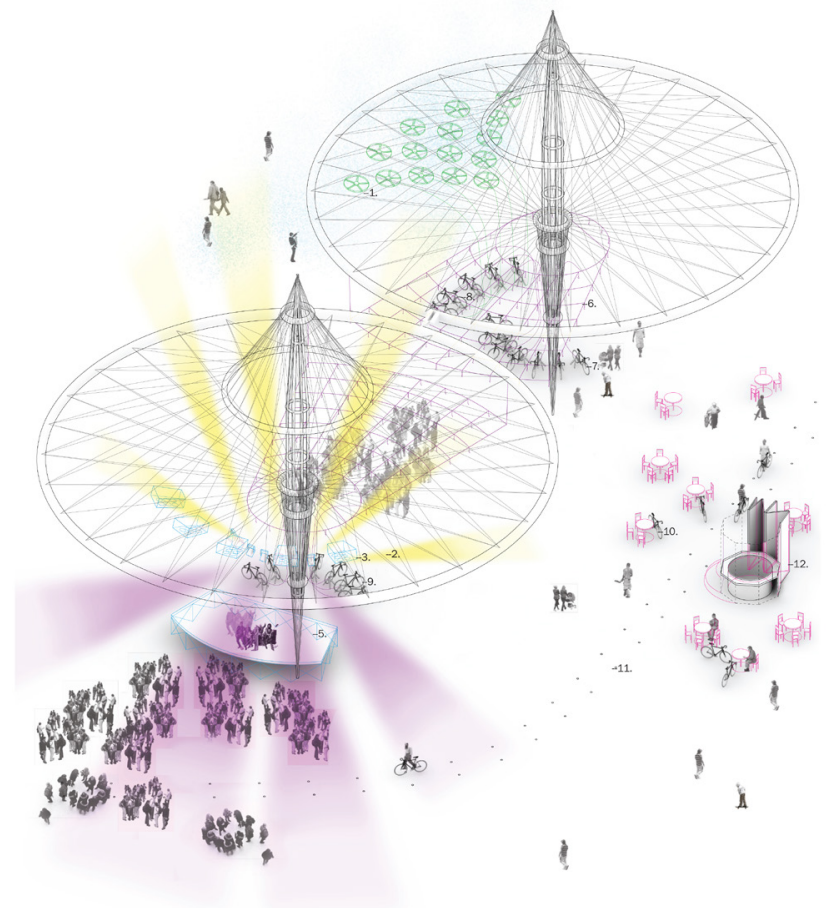

Figure 5: Isometric view of Structural Canopy enveloping social interaction of Velodrome Park. Fake Industries Architectural Agonism, 2012.

center of activity that allows people to have varying levels of control on how this architecture looks.

FKAA velodrome park focused on creating 'feedback loops of responsibility.' Since the city began providing more services in public spaces, the responsibility of citizens becomes something that the architect designs. FKAA's architecture employs a structural system resembling an aggregation of bicycle wheels, seen in their scaled design model that used bicycle wheel-sets to provide a conceptual and literal basis for their progressively engineered urban canopy, on top of the continuous park housing the velodrome.

The particular instrument of participation that FKAA developed was a mechanism that helps to open and close the façade of the park during the projects closed hours. The façade disappears when the velodrome is closed, but appears when it's in use becoming a continuous pavement. Grau states that, "when it (velodrome park) is open you have to define the limits, but when it is closed you don't." Cleverly, they placed the actual façade control mechanism on a stationary bicycle attached under their spoke-like canopy structures. This level of projective detail and interactive engineering engenders a particularly strange type of public responsibility. By distilling the activity of cycling into a structural system that resembles a bicycle wheel, allowing public control of the façade via pedaling activities and housing a velodrome, this project seems, at least conceptually, to be more of a bicycle than a bicycle itself. Currently under construction, the velodrome might become much more than icon, hopefully acting like an urban transformer anchored by a complex structural engineering that allows for projective participation through an almost techno-futurist aesthetic and lots of bicycles.

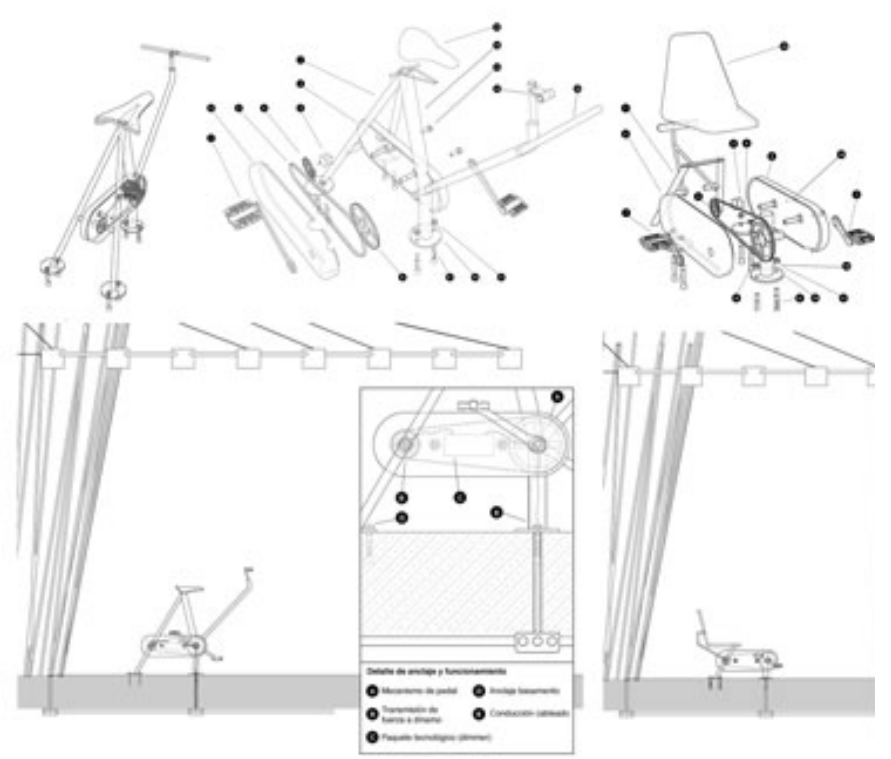

Figure 6: Isometric and component details for stationary bicycle mechanism. Studio IGG + FKAA, 2012.

\section{A STRANGELY OPTIMISTIC TRANSAMERICAN FUTURE?}

These Strangely Optimistic projects are underlined by a unique deployment of architecture's instruments. FKAA's Velodrome and Pedro y Juana's Randolph Square both use novel interactive design mechanisms - one urban and the other interior - to give up control of otherwise static and stoic architecture elements, while Mamani dazzles citizens of El Alto with super-aestheticized cultural urban buildings and hyper stylized interiors in his Salones de Eventos. All of their projects beg the question, might a Transamerican and nonEurocentric theory/practice of architecture emerge out of nuance and experimentation?

\section{Perhaps it too early to tell.}

Architecture does not need a general or accepted approach to be disciplined or valuable anymore. These three projects can affect the overall discipline of architecture, not from a top-down, modeloriented system or ideology, but from a horizontal, instance-oriented and participatory project. Strange Optimism is a Transamerican movement between the American continents and its people. Moreover, these projects exemplify how the lived experiences of Transamerican architects are important and potentially essential for the discipline at large. In lieu of macro-regionalist and hyper-globalized discourse, a Strange Optimism exalts individuality producing a localized and impactful disciplinary product that is relevant to particular publics, but perhaps not a whole world.

At least, not yet. 
1. Banham, Reyner. "The New Brutalism." Architectural Review (Dec. 1955): 354-361

2. The term 'Transamerican' is used here in two ways: first, to refer to the vast differences in geographic locations that the projects and practices of FKAA, Pedro y Juana and Freddy Mamani Silvestre occupy; and secondly, to challenge the cultural separation between North, Central and South America, not as an issue of distance, but one of culture, hence the use of the prefix 'trans' as between, not across.

3. Instrumentality in this essay is closely tied to a projective theory of architecture, as it differs from a more ubiquitous critical approach in Latin American architecture. Somol and Whiting state that, "For both (critical and projective), disciplinarity is understood as autonomy (enabling critique, representation, and signification), but not as instrumentality (projection, performativity, and pragmatics). One could say that their (critical) definition of disciplinarity is directed against reification rather then toward the possibility of emergence. While reification concerns itself with the negation of qualitative experience to quantification, emergence promises that serial accumulation may itself result in the production of new qualities." In Somol, Robert, and Whiting, Sarah. "Notes around the Doppler Effect and Other Moods of Modernism. "Perspecta 33 (2002): 73

4. Liernur, Jorge Francisco. Barry Bergdoll et al., "Architectures for Progress: Latin America, 1955-1980," in Latin America in Construction: Architecture 1955-1980 (New York: Museum of Modern Art, 2015), 77.

5. Ferraz, Marcelo Carvalho. "Stones Against Diamonds." AA Files, no. 64 (2012): 78-79.

6. Ibid. 78

7. Ibid. 79

8. Loomis, John A. Revolution of Forms: Cuba's forgotten Art Schools (New York: Museum of Modern Art, 2015): 58.

9. Ibid. 59

10. Pendleton-Jullian, Ann M. The Road That Is Not a Road and the Open City, Ritoque, Chile. (Chicago: Graham Foundation for Advanced Study in the Fine Arts, 1996.)

11. “About." Pedro Y Juana. N.p., n.d. Web. 28 May 2016.

12. Rudofsky, Bernard. Architecture without Architects: A Short Introduction to Nonpedigreed Architecture (New York: Museum of Modern Art, 1965.), iii.

13. Andreoli, Elisabetta. "Party Halls in El Alto, Bolivia by Freddy Mamani Silvestre." Architectural Review (July 2015)

14. It is important to note that a resurgence of postmodernism is palpable, with magazines such as AD's Radical Postmodernism published in September 2011, which included now defunct juggernauts FAT (Fashion Architecture Taste) in London getting international notoriety for their design and social agenda, as well as covering a Western academy-wide reinterest in architectural composition and representation. With this resurgence comes both a critique of the shortcomings of historicist postmodernism and its relationship to power, as well as the disciplinary products afforded to architects such as graphics, images, signs and forms to connect social opportunity to architectural disciplinarity. Mamani has been a cult figure in the last two years particularly because of the strange approach he has to his architecture, as well as the strange circumstance and opportunity his clientele have to produce expensive buildings that serve a primarily indigenous population

15. Katy Watson, "Indigenous Bolivia Begins to Shine under Morales," BBC News, , accessed June 28, 2016, http://www.bbc.com/news/ world-latin-america-29686249.

16. Mamani, Freddy. Interview with Nathalie Iriarte Villavicencio. Diario El Deber, September. 7, 2014

17. Grau, Urtzi. Interview with Andrew Santa Lucia. Skype interview. April 25, 2016. 